\title{
Effect of iodinated contrast media on thyroid: a brief review
}

\author{
Şerife Mehlika Kuşkonmaz ${ }^{1 *}$, Sema Yıldız \\ 'Department of Endocrinology and Metabolism, Güven Hospital, Ankara, Turkey, ${ }^{2}$ Department of Radiology, Dışkapı \\ Yıldırım Beyazıt Education and Research Hospital, Ankara, Turkey
}

\begin{abstract}
In parallel to the increased use of computed tomography, iodinated contrast agents are increasingly becoming a source of excess iodide. lodinated contrast agents may induce thyroid dysfunction in exposed patients, especially in the presence of an underlying thyroid disease. Thus, an ordinary dose of the contrast used for the imaging, can induce hyper or hypothyroidism in a patient with subtle thyroid disease. This review will briefly discuss the physiology of iodine and the clinical evaluation of iodine induced thyroid dysfunction.

Keywords: hyperthyroidism; hypothyroidism; iodinated contrast media
\end{abstract}

\section{INTRODUCTION}

In parallel to the increased use of computed tomography $(\mathrm{CT})$, iodinated contrast agents are increasingly becoming a source of excess iodide. Iodine content of intravenous contrast used routinely for a CT scan, highly exceeds the recommended daily dose of iodine intake. Iodinated contrast agents may induce thyroid dysfunction in exposed patients, especially in the presence of an underlying thyroid disease. This short review focuses on iodine induced hyper and hypothyroidism and alterations caused by contrast agents on thyroid scintigraphy.

\section{Role of iodine in normal physiology of thyroid}

Thyrocytes express the sodium iodide symporter (NIS) at their basolateral membrane, and transport

\footnotetext{
*Corresponding author: Şerife Mehlika Kuşkonmaz, Department of Endocrinology and Metabolism, Güven Hospital, Şimşek Sok No 29 Kavaklıdere 06540, Ankara, Turkey, Tel: 0903124572525, E-mail: mehlikaisildak@gmail.com
}

Submitted: 16 November 2015 / Accepted: 31 March 2016 iodide inside the cell through this gate and against an electrical gradient. Iodide is then organified into tyrosyl residues of thyroglobulin (TG), in a reaction catalyzed by thyroid peroxidase (TPO). Thyroglobulin (TG) contains monoiodothyronine, diiodothyronine, triiodothyrosine $\left(\mathrm{T}_{3}\right)$, and thyroxine $\left(\mathrm{T}_{4}\right)$ which are stored in colloid until $\mathrm{T}_{3}$ and $\mathrm{T}_{4}$ are released into the blood (1).

\section{Effect of iodinated contrast media on thyroid}

Radiographic iodinated contrast media (RICM) is increasingly becoming a source of excess iodide due to common use of CT scans (2). Low osmolar contrast media have fewer side effects and are preferable, especially in patients with renal dysfunction. However, they contain a higher ratio of iodide atoms (3).

Both ionic and nonionic contrast media contain iodine at amounts ranging between $300-370 \mathrm{mcg} / \mathrm{mL}$ (2). Usually, $50-100 \mathrm{ml}$ of contrast media is given per CT scan. This means that a patient undergoing a contrast CT scan receives about $15-37 \mathrm{~g}$ total iodine and 2500-5000 $\mu \mathrm{g}$ free 
iodine. Conversion of non-bioavailable iodine to free iodide in the body further contributes to the iodide load, especially in the presence of renal insufficiency (4). In patients with normal thyroid function, excess iodine persists in the body for 4-8 weeks after the exposure to contrast media (5).

Subtle changes (a small decrease followed by an increase in free T3 and free T4, and a decrease in TSH followed by a rapid increase - all within normal limits) in thyroid function, after the exposure to iodinated contrast media, can be detected in normal subjects (6).

\section{lodine induced hypothyroidism}

A retrospective analysis of patients exposed to contrast media showed an association between the contrast exposure and hypothyroidism. The duration between the exposure and incident hypothyroidism varied between 50-294 days (7).

In patients with a history of thyroid lobectomy, Graves' disease, postpartum thyroiditis, or Hashimoto's thyroiditis the follicular cells may fail to escape from the Wolff Chaikoff effect, after the exposure to excess iodine. As a result, iodine can induce hypothyroidism in these patients (8).

Other factors implied in iodine induced hypothyroidism are: down regulation of TPO (9), decreased organification of iodide (9), failure to decrease NIS expression (10), and autoimmunity (11).

Patients with underlying thyroid disease or patients who present with signs and symptoms of hypothyroidism, should be monitored for contrast induced hypothyroidism. If the TSH level is higher than $10 \mathrm{mIU} / \mathrm{L}$, the replacement with $\mathrm{L}$ thyroxine should be performed. Repeated TSH measurements in 6-12 weeks are necessary to titrate the dose. Contrast induced hypothyroidism is a self-limited dysfunction. The treatment may be stopped within a few months. However, continuous monitoring of these patients is suggested since they are under risk of permanent hypothyroidism, especially if they have an underlying thyroid autoimmunity (12).

\section{lodine induced thyrotoxicosis}

Iodine induced thyrotoxicosis was first described in 1821, and is known as Jod-Basedow phenomenon.
For iodine induced thyroid hyperfunction to occur, the Wolff Chaikoff effect need to be impaired. The risk factors for iodine induced hyperthyroidism include diffuse goiter, nodular goiter, latent Graves' disease, and iodine deficiency (13).

A study including 101 euthyroid patients who underwent coronary angiography, reported a $6 \%$ incidence of subclinical hyperthyroidism, 8 weeks after the exposure (14). A retrospective case-control study found a 2-3 times increased risk of hyperthyroidism after contrast exposure in patients with a prior history of thyroid dysfunction. The median follow-up period in this study was 9 months (7).

Other studies yielded contradicting results. No case of thyrotoxicosis was observed after iodine containing contrast exposure in 56 patients, in a study from the United States (15).

Another study from Italy on more than 1700 patients, reported an incidence of $1.9 \%$ hyperthyroidism after iodine exposure. However, in this study, anti-thyroid medications and radioactive iodine ablation were used in some of the patients, prior to the contrast exposure (16).

Elderly patients with probably undiagnosed thyroid nodules may develop subclinical hyperthyroidism (suppressed TSH and normal free T4 levels), as long as 8 weeks after the injection (17). These patients may present with atypical symptoms like weight loss and atrial fibrillation $(18,19)$. Thyroid dysfunction is associated with increased morbidity in elderly. Thus, it is important to consider thyrotoxicosis in elderly patients with non-specific symptoms and signs in the setting of recent contrast exposure.

Considering that iodinated contrast is a risk factor for thyrotoxicosis, the question is if all patients should be screened before performing a radiological procedure. Practically, the answer is "no".

The Contrast Media Safety Committee of the European Society of Urogenital Radiology (ESUR) published a guideline about iodine induced thyroid dysfunction, in 2015 (4). According to this guideline, routine monitoring of thyroid function before a CT scan is not indicated, however, patients under the risk should be carefully monitored after the exposure to iodine containing contrast media. Of note, the guideline states that manifest hyperthyroidism is an absolute contraindication for contrast enhanced imaging. 
Patients with thyrotoxicosis present with symptoms such as tremor, palpitations, excessive sweating, and weight loss. Laboratory tests show a suppressed TSH with elevated free T3 and free T4 levels. Since radioactive iodine uptake is inversely related to plasma iodine levels, low iodine uptake is observed in patients with contrast induced thyrotoxicosis. A spot urinary iodine level may be helpful for the diagnosis and in the follow-up (20). Repeated exposure to iodine should be avoided in these patients. Contrast induced thyrotoxicosis is a self-limited condition. Beta blocker or methimazole can be given to symptomatic patients.

Prophylactic treatment for iodine induced hyperthyroidism is a matter of debate. Data is insufficient to support the use of thionamides or perchlorate for the prevention (21). The Endocrine Society Guideline suggests prophylactic antithyroid therapy with methimazole or potassium perchlorate (200 mcg 2-3 times a day), in patients who have a high risk of contrast induced thyrotoxicosis or who have underlying cardiac arrhythmias (13).

In addition to thyroid dysfunction, contrast media exposure also precludes treatment with ${ }^{131}$ I for thyrotoxicosis or for differentiated thyroid cancer (DTC). Contrast exposure also affects the diagnostic accuracy of thyroid scintigraphy. The proper timing of ${ }^{131}$ I scintigraphy, after the exposure to intravenous contrast, is not known. So some authors suggest postponing a diagnostic scintigraphic study or radioactive iodine treatment for at least 2 months, after the exposure to intravenous contrast media $(22,23)$. However, a retrospective review of 1023 patients with DTC, who underwent a preoperative contrast enhanced CT scan, revealed similar urinary iodine excretion rates, measured at 1 month and 6 months after the contrast exposure (24).

Practical points:

- Patients with an underlying thyroid disease- e.g., Hashimoto thyroiditis or subtotal thyroidectomy - may develop hypothyroidism after exposure to iodinated contrast. Although the exact time for testing is not known, it seems feasible to monitor these patients within 6-8 weeks after the contrast exposure.

- Patients with an underlying thyroid disease- e.g., Graves disease or nodular goiter- may develop hyperthyroidism after exposure to iodinated contrast. Although the exact time for testing is not known it seems feasible to monitor these patients within 6-8 weeks after the contrast exposure.

- It is important to consider contrast induced thyrotoxicosis in elderly patients with atypical symptoms like weight loss and atrial fibrillation. Even subclinical hyperthyroidism is associated with increased morbidity in elderly patients.

- Repeated exposure to iodinated contrast should be avoided in a patient with a prior history of contrast induced thyrotoxicosis.

- Documented thyrotoxicosis is an absolute contraindication for procedures with iodinated contrast.

- Prophylactic treatment for iodine induced hyperthyroidism is a matter of debate. Thionamides or potassium perchlorate may be considered in patients with the high risk.

- Iodinated contrast exposure delays the treatment or diagnostic scanning of patients with differentiated thyroid cancer. So the radiologist and endocrinologist should coordinate for an appropriate timing of such a procedure or consider other diagnostic imaging methods, like magnetic resonance imaging.

\section{CONCLUSION}

Exposure to iodinated contrast media may induce hyper and hypothyroidism in patients, especially in those with an underlying thyroid disease, such as nodular goiter, Graves' disease, or Hashimoto's thyroiditis. Although routine screening with thyroid function tests is not feasible, careful evaluation of selected patients with risk factors is important. Special attention should be paid to elderly patients who may present with nonspecific symptoms and signs. Contrast exposure may also lead to unwanted delays in the management of differentiated thyroid cancer with radioactive iodine (RAI), so physicians should be careful about the proper indication and timing of contrast CT scans. Although contrast induced thyroid dysfunction is a self-limited state, follow-up of the patients for the development of a permanent thyroid disease is advised. 


\section{CONFLICT OF INTEREST}

The authors declare no conflict of interest.

\section{REFERENCES}

1. Schlumberger M, Lacroix L, Russo D, Filetti S, Bidart JM. Defects in iodide metabolism in thyroid cancer and implications for the follow-up and treatment of patients. Nat Clin Pract Endocrinol Metab 2007;3:260-9.

http://dx.doi.org/10.1038/ncpendmet0449.

2. Lee SY, Rhee CM, Leung AM, Braverman LE, Brent GA, Pearce EN. A review: Radiographic iodinated contrast media-induced thyroid dysfunction. J Clin Endocrinol Metab 2015;100:376-83.

http://dx.doi.org/10.1210/jc.2014-3292.

3. Solomon R, Briguori C, Bettmann M. Selection of contrast media. Kidney Int Suppl 2006;100:S39-S45.

http://dx.doi.org/10.1038/sj.ki.5000373.

4. Thomsen HS, Webb JAW, editors. Contrast Media: Safety issues and ESUR guidelines. Heidelberg: Springer Verlag; 2014.

5. Lee SY, Chang DLF, He X, Pearce EN, Braverman LE, Leung AM. Urinary iodine excretion and changes in thyroid hormone levels after computer tomography scan with iodinated contrast administration. Poster presented at: $84^{\text {th }}$ Annual Meeting of American Thyroid Association; October 29 November 2, 2014; Coronado, CA

6. Hehrmann R, Klein D, Mayer D, Ploner O. Risk of hyperthyroidism in examinations with contrast media [Article in German]. Akt Radiol 1996, 6:243-248.

7. Rhee CM, Bhan I, Alexander EK, Brunelli SM. Association between iodinated contrast media exposure and incident hyperthyroidism and hypothyroidism. Arch Intern Med 2012;172:153-15.

http://dx.doi.org/10.1001/archinternmed.2011.677.

8. Markou K, Georgopoulos N, Kyriazopoulou V, Vagenakis AG. Iodineinduced hypothyroidism. Thyroid 2001;11:501-510. http://dx.doi.org/10.1089/105072501300176462.

9. Oppenheimer JH, McPherson HT. The syndrome of iodide-induced goiter and myxedema. Am J Med 1961;30:281-288. http://dx.doi.org/10.1016/0002-9343(61)90099-7.

10. Eng PH, Cardona GR, Fang SL, Previti M, Alex S, Carrasco N, et al. Escape from the acute Wolfff-Chaikoff effect is associated with a decrease in thyroid sodium/iodide symporter messenger ribonucleic acid and protein. Endocrinology 1999;140:3404-10.

11. Braverman LE. Iodine and the thyroid: 33 years of study. Thyroid 1994;4:351-356.

http://dx.doi.org/10.1089/thy.1994.4.351.

12. Braverman LE, Ingbar SH, Vagenakis AG, Adams L, Maloof F. Enhanced susceptibility to iodide myxedema in patients with Hashimoto's disease. $\mathrm{J}$ Clin Endocrinol Metab 1971;32:515-521.

http://dx.doi.org/10.1210/jcem-32-4-515.
13. Roti E, Uberti ED. lodine excess and hyperthyroidism. Thyroid 2001;11:493-500

http://dx.doi.org/10.1089/105072501300176453.

14. Özkan S, Oysu AS, Kayataş K, Demirtunç R, Eren M, Uslu H, et al. Thyroid functions after contrast agent administration for coronary angiography: Aprospective observational study in euthyroid patients. Anadolu Kardiyol Derg 2013;13:363-9.

DOI: 10.5152/akd.2013.134.

15. Koroscil TM, Pelletier PR, Slauson JW, Hennessey J. Short-term effects of coronary angiographic contrast agents on thyroid function. Endocr Pract 1997;3:219-221.

http://dx.doi.org/10.4158/EP.3.4.219.

16. Marraccini P, Bianchi M, Bottoni A, Mazzarisi A, Coceani M, Molinaro S, et al. Prevalence of thyroid dysfunction and effect of contrast medium on thyroid metabolism in cardiac patients undergoing coronary angiography. Acta Radiol 2013;54:42-7.

http://dx.doi.org/10.1258/ar.2012.120326.

17. Conn JJ, Sebastian MJ, Deam D, Tam M, Martin Fl. A prospective study of the effect of nonionic contrast media on thyroid function. Thyroid 1996;6:107-10.

http://dx.doi.org/10.1089/thy.1996.6.107.

18. Martin FIR, Tress BW, Colman PG, Deam DR. lodine-induced hyperthyroidism due to non-ionic contrast radiography in the elderly. Am J Med 1993; 95:78-82

http://dx.doi.org/10.1016/0002-9343(93)90235-H.

19. Martin FIR, Deam DR. Hyperthyroidism in elderly hospitalized patients. Clinical features and treatment outcomes. Med J Aust 1996;164:200-203

20. Arum SM, HeX, Braverman LE. Excess iodine from an unexpected source. N Engl J Med 2009;360:424-426.

http://dx.doi.org/10.1056/NEJMc0807580.

21. Nolte, Muller R, Siggelkow H, Emrich D, Hufner M. Prophylactic application of thyrostatic drugs during excessive iodine exposure in euthyroid patients with thyroid autonomy: A randomized study. Eur J Endocrinol 1996;134:337-341.

http://dx.doi.org/10.1530/eje.0.1340337.

22. Martin WH, Sandler MP. Thyroid imaging. In: Sandler MP, Coleman RE, Patton JE, Wackers FJT, Gottschalk A, editors. Diagnostic nuclear medicine. $4^{\text {th }}$ ed. Baltimore: Lippincott, Williams \& Wilkins; 2003. p. 607-651.

23. Tuttle RM, Becker DV, Hurley JR. Radioiodine treatment of thyroid disease. In: Sandler MP, Coleman RE, Patton JE, Wackers FJT, Gottschalk A, editors. Diagnostic nuclear medicine. $4^{\text {th }}$ ed. Baltimore: Lippincott, Williams \& Wilkins; 2003. p. 653-670.

24. Sohn SY, Choi JH, Kim NK, Joung JY, Cho YY, Park SM, et al. The impact of iodinated contrast agent administered during preoperative computed tomography scan on body iodine pool in patients with differentiated thyroid cancer preparing for radioactive iodine treatment. Thyroid 2014;24:872-7.

http://dx.doi.org/10.1089/thy.2013.0238. 